Daniel Layman

\title{
ROBUST DELIBERATIVE DEMOCRACY
}

\begin{abstract}
Deliberative democracy aspires to secure political liberty by making citizens the authors of their laws. But how can it do this in the face of deep disagreement, not to mention imperfect knowledge and limited altruism? Deliberative democracy can secure political liberty by affording each citizen an equal position as a co-author of public laws and norms. Moreover, fundamental deliberative democracy - in which institutional design is ultimately accountable to public deliberation but not necessarily subject to its direct control — does not strain knowledge or altruism. Thus, there is a place for deliberative democracy in a robust political economy.
\end{abstract}

Keywords: deliberative democracy; incentive problems; knowledge problems; Mark Pennington; spontaneous order.

What, morally speaking, is so great about deliberative democracy? Does it offer moral benefits that classical liberalism cannot match? And, if it does, can it secure those benefits even in the face of the incomplete knowledge and limited altruism that characterize human social life?

In Robust Political Economy (Northampton, Mass.: Edward Elgar, 20 I I), Mark Pennington takes up these questions with insight, detail, and rigor, and the results of his analysis appear to be grim for deliberative democracy (50-79). According to Pennington, the deliberative democratic project-

\footnotetext{
Daniel Layman, dalayman@davidson.edu, Department of Philosophy, Davidson College, P.O. Box 7I32, Davidson NC 28035, thanks Benjamin Bagley, Patrick Connolly, Luke Elson, Jeffrey Friedman, Marija Jankovic, John Lawless, Sean McKeever, and Nathaniel Sharadin for helpful discussion and comments on earlier drafts.
}

Critical Review 28(3-4): 494-5I6

(C) 2016 Critical Review Foundation

ISSN 089I-38 I I print, I933-8007 online http://dx.doi.org/Io.I080/o89I38I I.20I6.I264I6I 
or perhaps, by his lights, the deliberative democratic dream—stands no chance against three damning problems. First, and most importantly, Pennington argues that deliberative democracy has nothing of moral significance to offer that spontaneous market and social orders cannot offer more efficiently (69-79). Let's call this the moral inferiority problem with deliberative democracy. Second, even if deliberative democracy could, in principle, offer a more attractive moral profile than spontaneous orders alone, there is the knowledge problem: people, whether singly or in groups, simply cannot acquire the knowledge about others, their needs, and their preferences that would be necessary to make deliberative democracy a success $(6 \mathrm{I}-65)$. Finally, there is the incentive problem: since it is very unlikely that anyone's vote or other deliberative contribution will make a difference to what a society decides to do, no one has an incentive to remedy her political ignorance or otherwise take her deliberative role seriously $(65-69)$. Thus, even if deliberative democracy could, in principle, be morally better than spontaneous order-based classical liberalism, any such arrangement would face two intractable practical roadblocks grounded in human nature.

Pennington's critique of deliberative democracy is just one strand of his broader project, which is to show that only a classical liberal political economy grounded in spontaneous order can secure a morally acceptable society that is robust against our inevitably incomplete knowledge and limited altruism. With the exception of one amendment, which I will discuss in the penultimate section, I accept Pennington's central robustness thesis: if a model of political economy cannot solve both the knowledge and incentive problems, we should reject it. I believe, however, that deliberative democracy, properly construed, does meet the demands of robustness while also offering moral benefits that non-deliberative classical liberalism cannot replicate. In particular, I will argue that deliberative democracy alone can secure citizens against dependence on others' personal wills by affording them a role as a coauthor of shared public norms. Consequently, there is a good moral case for deliberative democracy as the procedural foundation of a robust political-economic order.

I will proceed as follows. First, I will clarify the core features of deliberative democracy and classical liberalism and distinguish between what I call the policy version and the fundamental version of each position. Second, and most centrally to my argument here, I will argue that fundamental deliberative democracy is morally superior to fundamental classical liberalism on the grounds that fundamental deliberative democracy can 
secure citizens' independence from others' personal wills, while fundamental classical liberalism cannot. Third, I will argue that fundamental deliberative democracy is robust against the knowledge problem. Fourth, I will argue that fundamental deliberative democracy is, with some qualifications, robust against the incentives problem. I will conclude with some remarks about how my argument lays the foundations for at least a partial détente between classical liberalism and deliberative democracy

\section{Two Kinds of Deliberative Democracy (and Classical Liberalism)}

Following Pennington, I take classical liberalism to be fundamentally committed to two core insights, each of which concerns one of the two human frailties I mentioned in the introduction, and which a robust political economy must accommodate (3). ${ }^{\text {I }}$ The first, which is especially associated with Friedrich Hayek (I988), is that the range of socially useful knowledge any person or organized group can acquire and deploy is inevitably severely limited. People's goals, preferences, and interactions are far too complex to be objects of reliable centralized knowledge. The second insight is that incentives are important (e.g., Ostrom 2006). In short: People cannot be expected to behave in a prosocial way unless they stand to gain something by doing so. These two insights together generate a commitment to spontaneous order as the best means of structuring society and distributions within it. Pennington helpfully defines spontaneous order:

"Orders" of this nature exhibit patterns of coordination, but the regularities at issue are not the product of deliberate design by agents pursuing a unitary goal. Rather, they are "emergent" phenomena that arise from a variety of dispersed agents each pursuing their own separate ends. (4)

Spontaneous orders satisfactorily address the knowledge problem because they do not require any one agent to understand and respond to circumstances beyond the scope of her own interactions. And such orders observe the principle that incentives matter, because each of the discrete actions from which spontaneous order emerges is chosen by an individual agent pursuing her own goals. The classical liberal commitment to spontaneous order grounds its familiar appreciation of markets. In a 
(primarily) market society, individuals have a solid institutional platform on which to interact for mutual benefit, leading to the efficient communication of information through prices.

Let's now consider deliberative democracy. ${ }^{2}$ Like all democratic positions, deliberative democracy holds that some extensive class of social decisions should fall to the citizenry as a whole. But within democratic theory, deliberative democracy stands in contrast with both elite democracy and aggregative democracy. According to elite democracy, the people cannot exercise, and should not attempt to exercise, anything approaching direct control of anything. Following Joseph Schumpeter (I942), elite democrats hold that a small cadre of political elites inevitably shapes the beliefs and preferences of the people, so we should simply subject these elites to minimal democratic checks. According to aggregative democracy, the democratic process aims at moving from diverse individual preferences to optimal-which is to say, efficient-collective decisions (e.g., Arrow I963). Deliberative democracy, by contrast, sees the political process as one in which people do not attempt to instantiate their pre-existing preferences in policy, but instead work with their fellow citizens to reach sharable conclusions that reflect the reasons offered in the deliberative process. Since deliberative democratic citizens are expected to form and re-form their preferences as a result of the deliberative process they share, we can say that each citizen's position with respect to a topic of deliberation is endogenous to that process. Furthermore, nearly all versions of deliberative democracy impose a standard of public reason on the considerations citizens may offer in the course of deliberation. Perhaps most famously, Rawls (2005, I34-72) argues that these considerations must be justifiable on grounds acceptable to members of a variety of distinct reasonable "comprehensive doctrines," or worldviews, that form an "overlapping consensus" on citizens' status as free and equal and on accompanying basic liberties.

So far I have sketched deliberative democracy and classical liberalism in bare outline. I now want to address a crucial but underappreciated distinction between two forms that each of these views can take: the fundamental form and the policy form.

Policy deliberative democracy and policy classical liberalism are both views about how particular institutions or dimensions of institutions should operate. To endorse policy deliberative democracy about a particular good, service, or sector is to assert that a deliberating public should directly control that good, service, or sector. Similarly, to 
endorse policy classical liberalism about a particular good, service, or sector is to assert that spontaneous orders should directly control that good, service, or sector. In contrast, fundamental deliberative democracy and fundamental classical liberalism are views about the processes, groups, or systems to which public policies are ultimately answerable. According to fundamental deliberative democracy, public policy, whatever shape it might take with respect to a particular good, service, or sector, is subject to approval or rejection by citizens acting through an appropriately structured democratic process. This does not mean that deliberating citizens should exert direct control. But it does mean that questions of control ultimately rest with the deliberative public. According to fundamental classical liberalism, there should be no mechanism of social organization or decision making more basic than spontaneous order. By fundamental classical-liberal lights, spontaneous order is not just the best remedy for democratic publics to employ to address particular problems. Rather, the fundamental classical liberal denies that spontaneous order should answer to collective decision-making at all. ${ }^{3}$

To further clarify the distinction between the policy and fundamental forms of each view, it will be useful to consider an example. According to Amy Gutmann and Dennis Thompson (2004, I47-49), citizens should make decisions about funding for cervical cancer tests by deliberating about the merits of competing funding models. Consequently, we can say that Gutmann and Thompson endorse policy deliberative democracy about cervical cancer tests. In response, Pennington (20 I0) endorses policy classical liberalism with respect to cervical cancer tests. He argues that instead of deliberating about how to fund cervical cancer testing, we should allow a free market to determine test options and prices.

How do fundamental deliberative democracy and fundamental classical liberalism relate to this case? Fundamental deliberative democracy per se takes no stand on how to distribute cervical cancer tests. The deliberating citizenry might, for instance, decide that it is in the public interest for markets to dictate options and prices for such tests. If they were to do so, their selective dose of classical liberalism would be entirely compatible with a commitment to fundamental deliberative democracy. For proximate market control would then be licensed by, and accountable to, ultimate public control. According to fundamental classical liberalism, by contrast, spontaneous order should dictate the price and availability of cancer tests because (a) this is the mode of control that emerges from spontaneous order, thereby solving the knowledge and incentives problems; 
and (b) societies should employ no mechanism of ultimate decisionmaking or accountability more basic than spontaneous order. Fundamental deliberative democracy and fundamental classical liberalism might therefore render the same policy recommendations in some cases, albeit for different (ultimate) reasons.

My aim in this essay is to defend fundamental deliberative democracy against the three charges Pennington levels against deliberative democracy, which he appears to understand exclusively in its policy form. I will not, however, undertake to defend policy deliberative democracy in any sector. Whether deliberative groups should choose further deliberation or spontaneous order in particular cases is a highly complicated and empirically dependent question that I am not equipped to answer. But whether citizens should serve together as authoritative arbiters of political and economic institutions is a question of political morality to which a philosopher can reasonably hope to contribute. Unless otherwise noted, everything I say in defense of deliberative democracy should be understood to pertain only to fundamental deliberative democracy, not to policy deliberative democracy. And unless otherwise noted, all criticism of classical liberalism is criticism of fundamental classical liberalism, not policy classical liberalism.

\section{The Moral Case for Fundamental Deliberative Democracy}

According to Pennington, the central moral case for deliberative democracy is Iris Marion Young's argument in Justice and the Politics of Difference (1990), which turns on deliberative democracy's purportedly unique power to give minorities an effective voice. Pennington characterizes her case for deliberative democracy as follows:

The central moral argument for deliberative democracy is that it is more likely to reflect ethical norms of justice than bargaining in markets or market-like structures because it enables members of "excluded" groups including the poor and various cultural minorities to have their views registered in a public forum and to be heard with respect. (70)

Pennington then argues that in fact, markets promote minority voices more effectively than deliberation. Whereas it is unlikely that a parliamentary representative can adequately capture and express each individual's values and preferences, everyone can present her own values and 
preferences effectively and accurately through mutually beneficial private transactions (73). Moreover, they can do so regardless of their relative skill (or perceived skill) as persuasive writers or speakers (77-78).

These considerations are highly suggestive, and they might even be correct. Nevertheless, I will not engage them here, because-contrary to Young-I do not think that deliberative democracy's principle moral virtue is its promotion of minority voices. To the contrary, deliberative democracy's principle moral virtue is its capacity to secure citizens' liberty from others' personal power. ${ }^{4}$

Political liberty is a highly complex good that encompasses many dimensions. Contrary to theorists who insist on a single, univocal understanding of liberty, I am happy to allow that along several dimensions, freedom worth caring about is both positive (freedom to) and negative (freedom from). ${ }^{5}$

One important dimension of freedom, which has received recognition from authors as different as Hayek and Rousseau, is independent status. ${ }^{6}$ Someone who enjoys independent status does not have to depend on others' personal wills in order to enjoy important social goods or to occupy important social roles. Yet someone who lacks this dimension of liberty might nonetheless enjoy a great deal of unobstructed choice. Consider the famous example of the favorite slave. ${ }^{7}$ Such a slave might receive a great deal of money and influence from her master, who might demand little or nothing from her. But she nonetheless enjoys these goods (and indeed all other goods) at the discretion of her master. She enjoys freedom as non-interference, and perhaps other dimensions of liberty as well, but she does not enjoy freedom as independent status.

The moral intuition underlying the significance of independent status is reflected in the ancient maxim that a free person must be ruled by laws rather than by men. In every society, people must, in a variety of senses, be subject to others' judgments. Those of us attracted to freedom as independent status seek neither to deny this fact nor to achieve some kind of atomistic way of life that affords each person absolute independence. This dimension of freedom is, as Philip Pettit $(1997,67)$ puts it, a "freedom of the city," not a "freedom of the heath." But according to the ideal of independent status, subjection to others' judgments must never be subjection to their judgments simply as such. Rather, to the extent that I depend on others' judgments for important goods, their judgments must be constrained by a set of rules or norms that are answerable and justifiable to everyone, not just to those wielding power. 
Adam Smith and others following him have argued that free markets liberate people from the kind of personal dependence present in feudal and slave societies. ${ }^{8}$ Whereas a serf has a particular lord to whom she must answer, a worker may choose among prospective employers interested in purchasing her services. She may exit a particular employment relationship if she judges that is in her best interests to do so; and to the extent that she has a great deal to offer employers, they will be incentivized to compete with one another by offering her increasingly favorable terms. Thus, rigorously competitive markets are, according to this line of thought, an excellent (perhaps the best) remedy for dependent status.

It is certainly true that in a rigorously competitive market order, no one depends entirely on any one agent's will. For this reason, Smith was right to praise the fall of feudalism and rise of markets as a victory for liberty. However, the difference in personal dependence between a society fundamentally governed by feudal norms and one fundamentally governed by market norms is one of degree, not one of kind. For even when uneven power is highly dispersed within a market, it can still violate independent status, albeit to a lesser extent than in a system wherein individuals are subject to a single, identifiable master. Consequently, fundamental classical liberalism, in which spontaneous orders are the ultimate arbiters of institutional structure, is fully compatible with (attenuated) violations of independent status.

In order to better understand this point, it will be useful to introduce the idea of shared control. As I mentioned above, freedom as independent status requires that personal judgment regarding others' important opportunities be constrained by norms and rules responsive to all. Pettit has suggested-rightly, I think-that we should unpack this idea in terms of control. To borrow an example from him: I may, compatibly with my freedom from personal power, give a friend temporary control over my liquor cabinet in order to cut back on my drinking (Pettit 20I2, I 52). My friend has power over my choice, but only at my behest and on my terms, and at the pre-appointed time it will be up to me whether to continue his power or cut it off. Since my friend's power ultimately reflects $m y$ will rather than his, it is not merely a reflection of his personal judgment and, consequently, it does not infringe my liberty, understood as independence.

Now, it might seem that this understanding of liberty from personal power makes freedom in democratic society—or indeed any society- 
strictly impossible, and thereby pushes the independence theorist out of the city and onto the heath. ${ }^{9}$ After all, no one's will can personally control the operations of the state, so it might seem that no one can be free in a state. But deliberative democracy offers not separate control for each person, but rather co-authorship of a single, ongoing, collective act of control, wherein the controller is the people rather than any person or subgroup. ${ }^{\text {IO }}$ We can be free from personal power in deliberative democracy because we are free to contribute, as equal coauthors, to the fundamental norms and decisions that structure society's institutions.

Before proceeding with my account of how deliberative democracy can secure independent status, a clarification is in order. For my purposes, there is no need to endorse independent status as some kind of ultimate, trumping, or even lexically prior social good. To the contrary, one need only accept the claim - which I don't take to be very controversial - that independent status is a moral good worth having, even if other moral goods in society are more valuable. My aim in this paper is to show that we can have independent status through deliberative democracy without paying the kind of epistemic and motivational costs that worry classical liberals such as Pennington. Consequently, we need only make the modest assumption, shared by nearly everyone in the liberal tradition, that independent status is a good worth caring about to some non-trivial degree.

Let's return now to my description of the collective action of the democratic people as coauthorship. This is not idle metaphor. To the contrary, I believe that the distinctive logic of coauthorship, within which a group of people composes one and the same text, also characterizes deliberative democracy and affords it its liberating power. The control we share as democratic citizens is much more analogous to a group of people writing a book together than it is to each member of some plurality submitting inputs to a machine or exerting pressure on a physical object. Shared democratic control is not a matter of everyone submitting her own inputs or pressures to a system that manages them and renders a single outcome. Rather, it is a matter of everyone thinking about each input together, in light of the structure and aims of the whole process.

Consider textual coauthorship more closely. When some group of people authors a text together, their aim is to express, in one voice, a single coherent vision and line of argument. Moreover, what counts as a successful suggestion by one of the co-authors is largely endogenous to the ongoing activity she shares with the other coauthors. Its quality 
depends on the ongoing conceptualization of the project that is continually being produced by deliberation among the coauthors in light of their previous decisions. If someone agrees to coauthor a document with some others but then shows up at the writing session with a list of contents she wants in the final product, regardless of the process of creation in conjunction with the others, we would say that she is not really willing to be a coauthor at all. Rather, she wants to author her own ideas, using the writing process as a vehicle for them. True coauthorship is thus control of the creation of a text that is irreducibly collective. It is not control by any one author, nor is it each author's individual control aggregated into some kind of additive heap, as would be the case if each author wrote her bit separately and then tried to negotiate its inclusion. Each of the authors takes part in one and the same process of control, and for this reason, she may-and indeed should-lay claim, equally with the others, to the entire text.

As I understand and defend deliberative democracy, it is the ongoing coauthorship, by all of the citizens together, of decisions about fundamental norms and institutional structures that govern shared social life. Each citizen shares equally in one and the same process of control over what they will do, say, and allow as a people. Consequently, it is right to say that each person stands in a control relation to the power operative in the democratic process as a whole, and that she is the author of the democracy's outputs. Just as every sentence of a genuinely coauthored text is jointly attributable to each coauthor, each decision of a genuinely deliberative democracy is jointly attributable to each citizen.

We are now in a position to see why fundamental classical liberalism cannot free citizens from arbitrary power, whereas fundamental deliberative democracy can. Even if power in a market society is highly dispersed and impersonal, the institutional options and costs that result from that power are not equally attributable to each member of that society. Rather, they are more attributable to those with greater economic standing. This is not, of course, to say that an individual or group exercises sole, personal discretion in the way that a lord might in a feudal society. It is merely to say that since some people's decisions count for much more than others', the opportunities and costs faced by participants are more attributable to some than to others. Consequently, there is no coauthorship of power structures in place, and the better off exercise power over the worse off. This power, though in a real sense constrained by market pressures, is not accountable to the reasons and concerns offered by those 
subject to it. Fundamental deliberative democracy, by contrast, renders all power accountable to the single shared control of a community of equal coauthors to whom the resulting norms and policies are wholly attributable. The whole democratic output of law and policy is attributable to each citizen-coauthor in just the way that a whole text is attributable to each of its literal coauthors.

Before moving on, I want to distinguish my claim in this section from two other, closely related claims. First, I am not claiming that the capitalist class forms some kind of agent or quasi-agent. Unless the economically well off engage in anti-competitive collusion, which I am not here assuming, there is no reason to suppose that "the capitalists" en masse possess a will on which anyone is dependent. The wills on which people in spontaneous market orders are dependent are, instead, simply those of individuals and firms. Second, I am not claiming that relatively better-off members of a spontaneous economic order intentionally plan and carry out actions with the aim of supporting that order and their positions in it. ${ }^{\text {II }}$ Economic actors, including powerful ones, usually pursue their plans and projects without thinking at all about the larger order within which they operate, much less intentionally aiming to preserve it. My point is not that anyone intentionally maintains the economic system, but rather that some people within a fundamentally spontaneous order exert disproportionate influence within it, thereby rendering others' options asymmetrically dependent on their wills and preferences.

\section{Objections and Replies}

In this section, I will consider five possible objections to the moral defense of fundamental deliberative democracy I have been developing. Once we have dealt with these, we will be in a position to assess whether and how fundamental deliberative democracy can deliver its moral goods without falling afoul of the knowledge problem or the incentive problem.

First: how can democracy be at once deliberative in the way I have been describing and representative, as any large-scale democracy certainly must be?

While this problem is no doubt serious, I see no reason to think it intractable. One feasible step that would significantly increase the deliberative character of representative democracy would be to limit campaign activities to formal arguments and policy proposals offered in a standardized format using a standard, publicly approved budget. Another 
would be to replace individual votes for national office with local votes determined by direct deliberation at the local level. Still another would be to open public decisions to more avenues of public contestation. ${ }^{\text {I2 }}$ None of this amounts to anything like a concrete proposal. But all we need in the present context is reasonable hope that there are no insurmountable barriers to such a proposal's being given. And in light of these considerations and myriad others on offer in the democracy literature, it seems to me that there are grounds for such reasonable hope.

The second objection derives from some remarks Jason Brennan offers about the purported connection between democracy and autonomy. Brennan writes:

If there is a connection between voting and autonomy, it must be something like this: by voting, a person is in part the author of the laws... . Notice, however, that voting confers autonomy only if your side wins. (Brennan 2012, I8)

Brennan seems to reason that one governs oneself through the democratic process only insofar as one succeeds in using it to effect one's own preferences. This criticism relies on an aggregative conception of democracy, wherein people aim to secure through democratic machinery the exogenous preferences they bring with them to the democratic process. I am happy to grant that democratic autonomy is a prize for ideological winners if we understand democracy and its emancipatory potential in terms of aggregation. But I have been arguing that this is the wrong way to understand democracy and its emancipatory potential. In the deliberative picture I have articulated here, each deliberative citizen shares in one and the same coauthorship of shared norms. If coauthors of a text disagree on the direction in which a chapter ought to proceed, we do not attribute the resulting chapter only to those coauthors who supported the direction chosen. To the contrary, the text as a whole is equally attributable to all of the coauthors, because we take the coauthors to be engaged in an irreducibly collective and shared process of assessing reasons in order to express a single system of ideas. By the same token, deliberative decisions are jointly attributable to each member of the deliberative body, which is likewise engaged in an irreducibly collective and shared process of assessing reasons in order to express a single system of ideas.

The third objection comes from Pennington himself. He writes: "Procedures that rely on the statement of explicit reasons are more likely to exclude systematically those individuals who are less able to engage in 
the articulate persuasion of majorities" (77). Does deliberative democracy simply substitute a complex hierarchical structure of persuasive power for classical liberals' hierarchical structure of economic power?

I think not. For under deliberative democracy, it doesn't matter which deliberative citizens introduce the suggestions that finally win out, as long as those proposals are ones that each citizen can endorse as products of the deliberative procedure in which she shares.

Suppose that citizens are debating whether the state should manage the cost of education directly, or instead let supply and demand for educational goods establish prices for those goods. One citizen finds herself with a very clear set of reasons to believe that markets in education are best, while another finds herself in a general muddle about the whole topic. The former citizen presents her reasons to the latter citizen, who is then able to reflect and judge that she can accept those reasons, even though she could not have expressed them herself. In this scenario, one person is a much stronger and more confident participant in the process of deliberative democracy than another. But since this process is, essentially, one characterized by the shared aim of discovering jointly justifiable reasons, this is no problem for equality within it. Just as each coauthor of a text is the author of the whole text, including parts with respect to which another author was a much stronger contributor than she, public norms are attributable to each deliberative citizen, including those who are relatively unable to produce reasons bearing on questions at hand.

Although it is not a problem for deliberative democracy and its emancipatory potential for some people to attain a better track record than others when it comes to producing reasons that survive deliberation, it would be a problem if only a few elites could understand and rationally affirm the community's decisions. If the argumentative skills that tend to shepherd proposals through deliberation in a given polity are simply those of bamboozling others, then deliberative democracy isn't worth much. But as I noted earlier, the constraints of public reason-which aim to secure deliberation and outcomes that are sharable from a public point of view-are part of the structure of the deliberative democratic picture. Thus, a "deliberative" system pushed around by a few smoothtalking bullies or charlatans isn't really a system of deliberative democracy at all.

The fourth objection is that there can be no objectionable status dependence under fundamental classical liberalism because social and economic power is fluid. No one is assigned the position of a worker 
or a boss, for instance, and individuals and families can and do move up (and down) according to the success (or failure) of their efforts. Power and status within spontaneous order is mutable and contingent, not static and socially mandated. It certainly is true that there is more mobility of power and position within competitive spontaneous orders than within pre-capitalist orders, and this fact is much to the credit of competitive spontaneous orders. However, the success that supports mobility (and the failure that holds it back) is not straightforwardly within any individual's power. ${ }^{13}$ Myriad factors form a system of massive complexity that determines, to a considerable extent, how easy or difficult it will be for various individuals to succeed. No one person or group of people is responsible for the fact that a billionaire is better positioned for power in a market order than a pauper. Nevertheless, the billionaire is better positioned, and those who are well positioned bear a disproportionately powerful degree of influence on even the most faceless and complex spontaneous order.

The fifth and final challenge worth considering here is this: even if deliberative democracy does secure freedom as independent status more effectively than classical liberalism, classical liberalism secures freedom as agency more effectively than deliberative democracy. ${ }^{\mathrm{I}}$ Although deliberative democracy can render us free from asymmetrical dependence, only classical liberalism can afford us the space and choice to pursue our own projects in our own ways.

This criticism fails, for two reasons. First, the degree to which a person enjoys space to pursue her own preferences in her own way within a competitive spontaneous order depends, to a considerable extent, on her position within that order. If I am very poor and work eighty-hour weeks to survive, I might enjoy almost no such space at all. The fact that I might in principle rise to a better station in no way counts against the fact that the space of my agency is, at present, very severely constrained. Moreover, it is no use to point out that I am legally permitted to do more than I am in fact able to do, or that I could do more if I were able to incentivize others to go along with my preferences. If the issue at hand is space for free agency, it must be the extent of a person's actual action space that matters, not the extent of action space she would be permitted to enjoy if she did better in the market.

Second, even if we grant that market institutions are uniquely suited to facilitate individual agency, this counts in favor of policy classical liberalism but not fundamental classical liberalism. Suppose I judge that an acceptable 
level of individual agency is possible only when public institutions have extensive classical liberal features. This is a reason for me to defend extensively classical liberal institutions to my fellow citizens. For instance, it would be a reason for me to argue against policies that would give the state either a controlling stake in firms or the power to levy heavy taxes on entrepreneurial activity. It would not, however, be a reason for me to object to the requirement that I present and justify my view to my fellow citizens. And it is this latter requirement that is insisted upon by fundamental—rather than policy—deliberative democracy.

\section{Deliberative Democracy and the Knowledge Problem}

I have now sketched and defended what I take to be the primary moral case for fundamental deliberative democracy over fundamental classical liberalism: only fundamental deliberative democracy can secure independent status for all citizens. We now need to consider the knowledge problem and the incentive problem. If deliberative democracy makes unworkable demands on citizens' epistemic capacities, or if there is no reason to believe that morally ordinary people can be motivated to take deliberative democracy seriously, deliberative democracy will be untenable regardless of its moral merits. In the next two sections, I will take up these objections in turn, starting with the knowledge problem.

Recall the knowledge problem: the knowledge people would need to possess in order effectively to establish and pursue collective social goals is too complicated for any deliberative process to capture. This knowledge problem is both genuine and important, although I am unsure whether it is as severe as many classical liberals would have us believe. But even if we accept that social knowledge is as troublesome as classical liberals argue that it is, democratic polities are epistemically capable of securing the moral benefits I described in the previous section. This is true because deliberative democratic polities can accomplish the following two tasks, even if we assume the knowledge problem applies in its strongest form. First, they can define the appropriate moral parameters within which acceptable policy must operate. Second, democratic citizens can recognize, and express to one another, the limits of their explicit knowledge and deploy markets or other spontaneous orders to compensate for those limits. For fundamental deliberative democracy does not entail deliberative control at the policy level. 
Let's take to the case of medical coverage. Suppose that a democratic polity is faced with the question of whether and how to fund medical care for its members. The medical market is undeniably complicated, as indeed it must be in order to serve the diverse medical needs of the community. Consequently, it is highly unlikely that any single individual could plan and operate that market, let alone that a diverse and untrained group of citizens could do so. Nevertheless, a diverse and untrained group of citizens can understand, in general terms, what it would mean for the medical system to respect core norms of liberal political morality, such as fairness and equal respect.

Consider how a debate about medical policy in such moral-political terms might proceed. Citizen A argues that it is improper for the state to fund medical coverage, because this inappropriately treats citizens as dependent children rather than as independent adults. In order to respect citizens as independent adults, she argues, we must not publicly fund health care. In response, citizen B invokes the same liberal value of equal independence in support of the contrary position. According to $\mathrm{B}$, if we are to respect all citizens as independent equals, we must not allow anyone to become dependent on the vicissitudes of the market in order to secure her physical health. Pursuing this disagreement through a deliberative process does require a certain kind of knowledge, namely basic acquaintance with the core concepts that define liberal citizenship. It also requires the practical wisdom to frame and assess, on their moral merits, arguments offered within that framework. These, however, are not the sorts of knowledge to which the knowledge problem is supposed to apply. The knowledge problem afflicts attempts to connect a diverse and fluid set of personal goals and preferences with efficient solutions, not debates about the implications of shared moral concepts.

Now suppose that A and B's community has decided that the state must provide health-care support to all citizens. This raises the question of how exactly it ought to do so. Some possible approaches can be addressed, and perhaps ruled out, on moral grounds alone. For instance, the people might rule out any funding mechanism that would run afoul of the liberty to choose one's own profession. But once such unacceptable options have been ruled out, there will likely remain a number of broadly permissible approaches among which the community will have to decide. My second point concerning the knowledge problem naturally arises here: If the deliberative public lacks the knowledge to solve some problem deliberatively, it can and should endorse a non-deliberative 
approach to solving it. This might mean delegating the matter to experts, but in many cases, it might mean turning to a free market. For example, the public might decide that the best health-care option in light of its epistemic limits is a richly funded voucher system together with a marketplace of commercial hospitals, insurance firms, and pharmaceutical companies. This kind of move is, to be sure, incompatible with policy deliberative democracy in the arena of medicine. But it is not in conflict with fundamental deliberative democracy, which is the only form of deliberative democracy I am defending here.

One might grant this point but turn instead to incentives: Even if citizens can identify knowledge problems and, when appropriate, use markets in order to proceed in light of them, will they really be sufficiently incentivized to do so? Won't they attempt instead to seize the political process to further their personal aims, knowledge problems notwithstanding? This objection strikes me as just one specification the general incentive challenge to deliberative democracy. So let's turn to that challenge now.

\section{Deliberative Democracy and the Incentive Problem}

Recall Pennington's incentive problem for deliberative democracy: Since it is very unlikely that any individual will be able to effect any particular outcome by democratic means, individuals lack a sufficient incentive to take democracy seriously. They will be rationally ignorant of political affairs, and they will be disinclined to devote time, energy, and resources to the political process. It is true that it is highly unlikely that an individual will cast a vote that will determine whether her preference carries the day. Moreover, although the odds of effecting one's pre-deliberative preferences through a process of collective deliberation may (or may not) be slightly better than those offered by voting alone, such odds are far from a sure bet. Thus, if we insist that the only incentives that can motivate citizens are incentives grounded in the likelihood of securing their pre-deliberative preferences, deliberative democracy does not provide adequate incentives for citizens to take it seriously.

However, insisting on this point is hardly fair to the deliberative democrat. For the opportunity to effect pre-deliberative preferences is not what deliberative democracy purports to offer. Rather, it purports to offer the opportunity to share equally in the process of authoring the norms and institutions by which one will be bound along with others and, 
thereby, the opportunity to achieve freedom as independent status. Deliberative democracy does not ask citizens to put aside what is good for them or to sacrifice themselves for others. If it did, it would surely be untenable. Instead, it asks people to conceptualize their good as centrally depending on freedom from slavish dependence on others' personal wills. If someone genuinely does not care about suffering such dependence, it is not clear why she would be motivated to care about deliberative democracy.

I have been claiming all along that I mean to find a place for deliberative democracy within a robust political economy. But have I compromised this aim by granting that those who don't care about their own domination lack an effective incentive to take seriously their roles as democratic citizens? I have not. According to the robustness thesis, an adequate political economy secures important goods for all even when people are widely ignorant and imperfectly altruistic. Pennington does not offer an explicit statement about what goods count as important for the purpose of assessing the robustness of political economies. But the examples of such goods that he does offer-which include health, education, wealth, and environmental protection-suggest that he has in mind goods that everyone has reason to value, whatever else they might value (I). We can follow Rawls in calling such goods primary goods. According to Rawls, primary goods include not just morally neutral goods such as wealth and health, whose value is independent of moral commitments, but also irreducibly moral goods, such as the social bases of self-respect. The value of irreducibly moral primary goods depends on moral commitments that individuals reasonably ought to have, such as a commitment to seeing themselves as worthy of equal status and respect. It is not clear whether Pennington means to endorse irreducibly moral primary goods along with morally neutral primary goods. But my moral case for deliberative democracy depends on accepting at least one irreducibly moral primary good: independent status. This good is irreducibly moral because it is only important to those who value as morally significant their independence from others' unaccountable power. If someone does not judge that this dimension of her relationships with others is morally significant, she is unlikely to value her independent status.

Now, it is true of all social goods that, ceteris paribus, more robust protection is better than less robust protection. But once we allow that some irreducibly moral goods are among the primary goods, we may need to relax, if only slightly, the degree of robustness we demand of our political 
economy. For although we can rely on people to care about morally neutral primary goods no matter what else they might care about, the same cannot be said for irreducibly moral primary goods. If someone simply doesn't care about her social position, she won't be incentivized to take steps to secure it. Consequently, we are faced with a choice. On the one hand, we might opt for a sparse lineup of primary goods that excludes irreducibly moral goods. If we do so, we can demand robustness of the utmost rigor against the stubborn fact that incentives matter. For if the primary goods to be secured include only those that every instrumentally rational person has an incentive to pursue, incentive problems could, in principle, be limited to those very few individuals who are instrumentally irrational. On the other hand, we might include independent status, which is irreducibly moral, among the primary goods. If we do so, we must relax somewhat the standard of acceptable robustness, at least when it comes to incentives. For we must grant that there might be instrumentally rational people who nonetheless don't value themselves enough to care about their independent status. Consequently, if we count independent status as a primary good and structure our political institutions accordingly, we risk a slightly higher rate of incentive problems than if we counted only non-moral goods as primary goods. That is, a political economy that includes as primary such irreducibly moral goods as independent status is slightly less robust - which is to say, it secures its specified goods under slightly more constrained circumstances - than a political economy that countenances only morally neutral primary goods.

Does the need to trade off some small degree of robustness for independent status pose a serious problem for fundamental deliberative democracy? It would pose a serious problem if robustness per se were lexically prior to all other social goods. But robustness is only as important as the goods it robustly secures. If independent status is morally significant to even a moderate degree, we should be willing to accept some small reduction in the robustness of our political and economic system in order to protect independent status therein. And for reasons I have been exploring in this essay, there is good reason to believe that independent status is at least moderately morally significant, if not more so. Thus, unless there is some political system that secures independent status just as well as deliberative democracy while also motivating absolutely every instrumentally rational person to take seriously her role in the system, the slight reduction in robustness that comes with deliberative democracy is well worth the moral payoff it offers. 
Someone might press further still: Doesn't empirical evidence overwhelmingly suggest that people largely choose to remain politically ignorant, eschew voting, and otherwise disregard their roles as citizens? It certainly does. ${ }^{\text {Is }}$ But few contemporary democratic polities are even remotely deliberative in their structure. Many people see the extant political process - not entirely unreasonably — as little more than a rigged machine over which the distant powerful squabble for their own purposes. They rightly identify little correlation between showing up at the polls and their own emancipation. My claim here is not that extant democratic institutions secure independent status while respecting the limits of knowledge and altruism. Rather, it is that fundamental deliberative democracy, which does not actually exist, could secure independent status within these limits. While there are no doubt many obstacles between us and a political future characterized by fundamental deliberative democracy, the epistemic and motivational limitations of human beings per se are not among them.

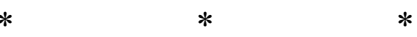

Under the influence of Hayek, classical liberals have taken deliberative democracy to be paradigmatically at odds with their most important insights. Indeed, an aggressively deliberative approach to public justification has struck most classical liberal theorists as manifesting a reckless, devil-may-care attitude toward social reality and human limitations. Moreover, as Pennington articulates so clearly, the deliberative democrat seems to indulge in this risk-seeking behavior in vain, since all of the moral payoffs she seeks are available, risk free, from spontaneous order. I have tried to show the way towards a kind of peace between classical deliberative democracy and classical liberalism. Deliberative democracy, at least in its fundamental form, is uniquely capable of securing our freedom while still heeding the classical liberal warning that has rung out since the Scottish enlightenment: we must never commit our merely human lives to a system built for creatures smarter and saintlier than we can ever hope to become.

\section{NOTES}

I. It is important to distinguish the classical liberalism under discussion here from libertarianism as a system of political morality. According to libertarian political morality, individuals hold very strong natural property rights that render most government intrusion immoral. While classical liberals may endorse libertarian 
political morality (and some do), they need not do so, and I will not assume that they do. In particular, I do not mean to attribute any such political morality to Pennington. For a treatment (but not an endorsement) of libertarian political morality, see Brennan and Jaworski 20I6, 22-23.

2. The literature on deliberative democracy is enormous and highly various. Two important strands of contemporary deliberative democratic thought are grounded in the work of Jürgen Habermas (I984) and John Rawls (I996). While Habermas takes a critical-theory approach that emphasizes the need to free communication from the grips of ideology through rational discourse, Rawls emphasizes deliberation as way for citizens to arrive, through the exchange of publicly valid reasons, at institutions justifiable to all.

3. Pennington seems to endorse a version of wide classical liberalism insofar as he urges that even political entities should emerge from, and remain subject to, spontaneous competition with one another: "The state . . a although a particularly powerful organization should be just one of many other similar organizations, constrained in its powers by the existence of competitors" (6).

4. Readers will recognize the idea of freedom from personal power as one central to recent "neo-republican" works by Philip Pettit (I997, 200I, and 20I2), Frank Lovett (2012) and Quentin Skinner (1997), among others. While my argument here is highly indebted to these authors, I resist the republican label, since I reject the notion that there is anything like a sharp distinction between the republican tradition and a separate liberal one. For other recent (though slightly different) arguments to the effect that deliberative democracy secures freedom from personal power, see Rostbøll 2008 and Gourevitch 20I3. It is also important to distinguish my position from that of Carol C. Gould. According to Gould, participatory democracy supports positive freedom as self-development (Gould I988). She might be right about this, but my thesis is about the relationship between deliberative democracy and the absence of personal dependence, not the presence of the capacity for self-development.

5. Rostbøll (2008) is right, I think, to distinguish dimensions of political freedom from conceptions of political freedom. Different conceptions of freedom are different ways of analyzing the concept of freedom. As such, they are inherently competitive. If, for instance, the "republican" conception of freedom as non-domination is right, the "liberal" conception of freedom as non-interference (e.g., Kramer 2008) is wrong. Different dimensions of freedom, by contrast, are different ways freedom manifests itself in relation to different moral and social demands, or under different circumstances. As such, different dimensions of freedom are not necessarily incompatible with one another; freedom may have, for instance, both a non-domination dimension and a non-interference dimension.

6. Hayek ([I960] 20I I, 59) endorses the "time-honored" definition of freedom as "the possibility of a person's acting according to his own decisions and plans, in contrast with the position of one who was irrevocably subject to the will of another." Similarly, Rousseau (I997, 9) writes in the Discourse on Political Economy: "If someone can compel my will, I am no longer free."

7. For discussion of this example, see Pettit I997, 22-23.

8. Smith ([I776] I98 I, 400) writes of the "burghers" who emerged with early capitalism and the corresponding demise of feudalism: "The principal attributes of villanage and slavery being thus taken away from them, they now, at least, became really free in our present sense of the word Freedom." For a contemporary development of the idea that markets secure independent status, see Taylor 20I3. 
9. For remarks in this spirit, see Gaus 2003 and Brennan and Lomasky 2006.

Io. Pettit expresses a similar idea: "The only way in which the state can operate effectively and yet satisfy the demands of republican legitimacy is by giving each of its citizens an equal share in a system of joint control" (Pettit 20I2, I68).

I I. Alex Gourevitch defends a version of this view. See Gourevitch 2013.

I2. Pettit emphasizes public contestation in his own account of independence-preserving democracy. See Pettit 20I2, 2I3-I4.

I3. G. A. Cohen has effectively pointed out that even if any individual could, at any time, rise in the socio-economic hierarchy, this does little to ameliorate the moral character of that hierarchy if any individual's ascension to a better socio-economic place is contingent upon others failing to do so. Where the ability to take advantage of an opportunity is thus conditional on others failing to do so, we may say that people are "collectively unfree" with respect to that opportunity, even if each individual is free with respect to it. See Cohen 2006, I80-I 82

I4. John Tomasi (2012, I80-96) offers an argument along these lines.

I5. For a treatment of this literature and some of its implications, see Somin 2013.

\section{REFERENCES}

Arrow, Kenneth. 1963. Social Choice and Individual Values. New Haven: Yale University Press.

Brennan, Jason. 2012. "Political Liberty: Who Needs It?" Social Philosophy and Policy 29: $\mathrm{I}-27$.

Brennan, Jason, and Peter Jaworski. 20 I6. Markets without Limits. London: Routledge. Brennan, Geoffrey, and Loren Lomasky. 2006. "Against Reviving Republicanism." Politics, Philosophy, and Economics 5: 22 I-52.

Cohen, G. A. 2006. "Capitalism, Freedom, and the Proletariat." The Liberty Reader, ed. David Miller. Boulder: Paradigm.

Dryzek, John. 2000. Deliberative Democracy and Beyond: Liberals, Critics, Contestations. New York: Oxford University Press.

Gaus, Gerald. 2003. "Backwards into the Future: Neorepublicanism as a Post-Socialist Critique of Market Society." Social Philosophy and Policy 20: 59-9I.

Gould, Carol. 1988. Rethinking Democracy: Freedom and Social Cooperation in Politics, Economy, and Society. Cambridge: Cambridge University Press.

Gourevitch, Alex. 2013. "Labor Republicanism and the Transformation of Work." Political Theory 4I: 59I-6I7.

Gutmann, Amy, and Dennis Thompson. 2004. Why Deliberative Democracy? Princeton: Princeton University Press.

Habermas, Jürgen. I984. The Theory of Communicative Action. Boston: Beacon Press.

Hayek, Friedrich. I988. The Fatal Conceit: The Errors of Socialism, ed. W.W. Bartley III. Chicago: University of Chicago Press.

Hayek, Friedrich. [ı66] 201 I. The Constitution of Liberty: The Definitive Edition, ed. Ronald Hamowy. Chicago: University of Chicago Press.

Kramer, Michael. 2008. The Quality of Freedom. New York: Oxford University Press. Lovett, Frank. 20I0. A General Theory of Domination and Justice. New York: Oxford University Press. 
Ostrom, Elinor. 2006. Understanding Institutional Diversity. Princeton: Princeton University Press.

Pennington, Mark. 20 I I. Robust Political Economy. Northampton, Mass: Edward Elgar.

Pennington, Mark. 20 Io. "Democracy and the Deliberative Conceit." Critical Review 22: I 59-84.

Pettit, Philip. I997. Republicanism: A Theory of Freedom and Government. New York: Oxford University Press.

Pettit, Philip. 20I2. On the People's Terms: A Republican Theory and Model of Government. Cambridge: Cambridge University Press.

Rawls, John. I995. Political Liberalism: Revised Edition. New York: Columbia University Press.

Rostbøll, Christian. 2008. Deliberative Freedom: Deliberative Democracy as Critical Theory. Albany: State University of New York Press.

Rousseau, Jean-Jacques. I997. "The Social Contract” and other Later Political Writings, ed. Victor Gourevitch. Cambridge: Cambridge University Press.

Schumpeter, Joseph. I942. Capitalism, Socialism, and Democracy. New York: Harper \& Row.

Skinner, Quentin. I997. Liberty Before Liberalism. Cambridge: Cambridge University Press.

Smith, Adam. [1776] I98 I. The Wealth of Nations. Indianapolis: Liberty Fund.

Somin, Ilya. 20 I 3. Democracy and Political Ignorance. Stanford: Stanford University Press.

Taylor, Richard. 2013. "Market Freedom as Anti-Power." American Political Science Review I07(3): 593-602.

Tomasi, John. 2012. Free Market Fairness. Princeton: Princeton University Press.

Young, Iris Marion. I990. Justice and the Politics of Difference. Princeton: Princeton University Press. 